DOI: 10.1515/ausfm-2015-0034

\title{
Digitalization and the Production of Feeling and Emotion: The Case of Words Cut into the Skin ${ }^{1}$
}

\author{
Hans T. Sternudd \\ Linnaeus University, Växjö, Sweden \\ E-mail: hans.sternudd@lnu.se
}

\begin{abstract}
This article investigates one example of how affect is articulated in the self-cutting of words into the skin and how the meaning of this multimodal statement is modified through remediation. According to Tomkins, affects are understood as intensities that are impossible to frame as feelings or emotions. A theoretical framework based on Laclau's and Mouffe's discourse theory and the multimodal categories developed by Kress and van Leeuwen is used. Photographs of self-cutting and statements from people who cut themselves are examined through content analyses. The results show that words that had been cut into the skin often referred to painful experiences, disgust directed against themselves, or social isolation. Further, the study shows that when the cut-in words are remediated through a photograph, digitalized and published online, other meanings appear. Inside internet communities for people who self-injure, the photographs were associated with a communal experience, identification and prescribed activity. The original self-oriented feelings about one's shortcomings and isolation attached to self-cutting could be altered so that those connoted, instead, experiences of solidarity, identity and intimacy.
\end{abstract}

Keywords: self-cutting, pain, affect theory, discourse theory, multimodality, remediation.

\section{Introduction}

The digitalization of post-industrial societies has affected all articulatory practices, from the production of means for living and pleasure to economic and other interpersonal relations. This article will address one aspect of this digitalization:

1 This article is based on a paper presented at the conference of the International Society for Intermedial Studies, Rethinking Intermediality in the Digital Age, 24-26 October 2013, Sapientia Hungarian University of Transylvania. 
how individuals' understanding of so-called inner experiences is constituted in part by remediation to digitalized media, ${ }^{2}$ in this case as photographs of words cut into the skin published on the internet. ${ }^{3}$

Photographs of self-inflicted injuries have, during the last few decades, constituted a genre of images with special visual characteristics and practices. They occur frequently on internet sites and forums focusing on self-destructive issues, on blogs and image-hosting sites such as Flickr, Photobucket and Instagram, or on other sites such as Tumblr, Pinterest and Weheartit, where users share text- and image-based material. The production and spreading of self-injury photographs is part of a culture in which almost every aspect of life is "documented" and shared on a worldwide scale (see, e.g. Murray 2008). Meeker (2013) reports that over 500 million photographs were uploaded and shared on a selection of social media every day in 2013. ${ }^{4}$ This almost inconceivable production is possible because the means for production has been made available to the majority of the population in post-industrial countries. Through digitalization, sophisticated equipment for media production has become easy to use, cheap and portable. The sharing of these media products has, with the development of Web 2.0, become possible for a wide range of people, including subjected social segments, such as adolescents who are involved in deviant activities as, among others, self-cutting.

In this study, I will focus on the subgenre of photographs of self-inflicted injuries that depict words cut into the skin. With their use of (presumed) physical, visual and verbal modes, they are of special interest for intermedial studies. The purpose of the study is to investigate how pain is articulated through different mediums and how these statements, through digitalization, become part of an alternative discourse that challenges a hegemonic understanding of self-cutting activities. Using a theoretical framework developed in the fields of discourse theory, affect theory and social semiotics, I will address the following questions: 1) How is the meaning of pain articulated through language and a sharp object?

2) Does the remediation through digitalized photographic and distribution means qualitatively alter the meaning of words cut into the skin?

3) In what way does the digitalized mediation of statements of individuals who experienced self-cutting influence a discursive understanding of feelings and emotions that are or become part of the act?

2 Remediation is, according to Bolter and Grusin, understood as "the representation of one medium in another" (1996, 339).

3 This article is based on my research on photographs of self-inflicted injuries published on the internet: results published in Sternudd 2010; 2011a; 2011b; 2012; 2014a.

4 The selected media were Facebook, Instagram, Snapchat, Flickr. 
Self-cutting is understood here as a practice which is related to self-injury and is predominantly understood as a "direct, deliberate destruction or alteration of one's own body tissue without conscious suicidal intent” (Favazza 1996, 225). This concept is reflected in the fifth version of the influential American Psychiatric Association's Diagnostic and Statistical Manual of Mental Disorders, DSM-5 (2013, 803-806). Self-cuttings, the photographs and the mediation of these are understood here as discursively based statements or articulatory practices. The kind of selfharmful practice which is addressed in this article is executed with the intention of obtaining relief from negative states of various kinds $(2013,803)$. This means that self-inflicted injury performed as a cultural and social practice is not discussed here. Self-cutting was the only method for self-injury used in this sample.

\section{Previous Research}

There are only a few studies on photographs of self-injury. Apart from my own in the project The Semiotics of Pain (2008-2011, see note 2), there are also the studies of Lewis, Heath, Sornberger and Arbuthnott (2012), Baker and Lewis (2013) and Seko (2013). Photos of words cut into the skin have been briefly analysed in my research (Sternudd 2010, 241; 2011b, 86-88) and more thoroughly in Bandalli's psychological study $(2011,116-127)$. Bandalli understands self-injury as a way of expressing and communicating "inexpressible emotions and issues" (Bandalli 2011, 51). Considering this inexpressibility, he presumes, a bit inconsistently, that words cut into the skin can provide an understanding of "the content which acts of DSH may serve to express or communicate, and the subjects to which they refer" $(2011,117) .^{5}$ In his study, Bandalli identifies six main themes (Bandalli 2011, 121-127), among which statements related to emotional states were most frequent. Words such as alone, numb, lost, hurt and trapped were included in this category. Bandalli suggests that the most frequent words and phrases in his data reflect "the key issues which are of most importance or concern to the individuals who inflicted these injuries" (Bandalli 2011, 126). Thus, the "high frequency of the word 'alone"' indicates that the most common issues would be "feelings of isolation and loneliness." One problem with Bandalli's study is that he does not know anything about the producers of the photographs and because of that, as he points out, it is not "possible to interpret the subjective meaning of the words and phrases the perspectives of those individuals who engraved them into their skin” (Bandalli 2011, 118).

$5 \quad$ Bandalli uses the term deliberate self-harm (DSH) much in the same way as self-injury is used in this article. 
Instead of using a theory based on notions of expression and communication, my approach is influenced by affect theory. This means that the perspective is turned around, and cutting words into the skin becomes an articulation that uses meaning systems (discourses) to make (as Bandalli puts it [2011, 51]) the “inexpressible emotions and issues" intelligible.

\section{Theoretical Approach}

Having this theoretical approach means that the study is grounded on nonessentialist and constructivist ontology. Its reasoning is founded on the notion that signifying systems make the world meaningful to us and that the world approaches us already interpreted through semiotic systems (Sonesson 1992, 12).

Affect, feelings and emotions have, since 2000, become a rapidly growing research field, to such an extent that this has been called an affective or emotional turn (Öhman, Jönsson and Svensson 2011, 11). The concept of affect, as outlined by Tomkins (1995), is central to the argumentation in this text. Affect is understood as a sensation experienced by the individual; it is an "amplification of urgency" (Tomkins 1995, 54), an intense experience craving for action. Shouse (2005) describes affect as an abstract pre-personal intensity that "cannot be fully realized in language." The idea of the unspeakable affect is important for the logic of this paper, and I shall return to it later. Feelings, on the other hand, are affects that have been understood through language and labelled (Shouse 2005). If the subject has previous experience, the process of "feeling-making" becomes easier. In addition, feelings are how it feels for a subject, which, at least theoretically, can be separated from emotions, which are defined as "social qualities that we communicate with in social situations" (Öhman, Jönsson and Svensson 2011, 11, translated by the author), for instance sorrow, love, shame, hope and wrath. Emotions explain feelings by contextualizing them and shaping them into a socially understandable discourse.

Using the word language, as in Shouse's article, gives an association to a linguistic system that narrows the understanding of how meaning is constructed. Instead, the concept of discourse is more appropriate here. Discourse theory (DT), as described by Laclau and Mouffe (2001), opens up understanding to a wider range of signifying systems (which includes every social practice). Meaning, according to DT, is something that is produced in a contextualized social activity, an ongoing process that makes meaning contingent. Signs achieve meaning by way of their position in a network that consists of other signs through a chain of 
equivalences (Laclau and Mouffe 2001, 110) and oppositions. A sign in a system that has no definite meaning is called an element. When an element has obtained meaning it becomes a moment. Articulation indicates a temporary halt in the constant shift of meanings. Laclau and Mouffe argue that "every social practice is [...] articulatory" (Laclau and Mouffe 2001, 113). Consequently, cuttings, words and photographs in their analogue or digital appearance are treated as articulatory practices in this text.

Returning to the concept of "unspeakable," understandings of pain often draw on its chaotic and system-threatening character. Pain, in a similar way to affect, has been described as something intense, "something" that is too much, "an excess of sensory input, such as for example excess of cold or sound or light" (Kalman quoted in Sternudd 2011b, 15-16). In this way, pain is, at least theoretically, connected to affect. This connection is observed by Tomkins, who writes: "The affect mechanism is like the pain mechanism in this respect [...]. If we cut our hand, saw it bleeding, but had no innate pain receptors, we would know we had done something which needed repair, but there would be no urgency to it" (Tomkins 1995, 88).

Tomkins's example seems reasonable - affect makes feelings "feel” by giving them intensity, but studies on self-cutting experience show that people's "pain mechanism" does not always follow Tomkins's scheme. In many studies of statements by people who cut themselves, the absence of pain is typically reported (e.g. Darche 1990; Favazza 1996; Favazza and Conterio 1989; Walsh and Rosen 1988). Even if pain is often considered an issue for those who cut, it does not have to be nociceptive, nerve-transmitted pain. Pain-as-chaos can include nociceptive pain, but not necessarily. I have argued before that feelings can become too much and therefore painful (Sternudd 2011b, 89; 2014b). In the light of affect theory it would be more correct to say that affects (not feelings) can be equated with pain in pain-as-chaos theory.

The insufficiency of language to articulate the inner experience is an oftenoccurring notion among persons involved in self-injuring activities. For example these activities are described "as a method of expressing emotional pain in a non-verbal manner” (Bandalli 2011, 29). From an affect-theoretical perspective, this method is logical. Shouse uses the example of an infant who is experiencing intensities and whose lack of language and previous experience cannot articulate them as feelings. Therefore the infant can only "express the intensity of the stimulations that impinge upon them" with intense activities (Shouse 2005, section 6) such as screaming. A functionalistic explanation of self-injury could follow a 
logic that states that it is the overwhelming intensity of the affect (pain) that triggers people to self-injure. If so, self-cutting can be understood as an attempt to articulate the affect and thereby control and master it. Words cut into the skin could therefore be seen as a complement to the meaning that is constituted through other modes: visual sights of blood and wounds, and nociceptive stimulation.

\section{Method and Material}

My study is based on three major sources. The photographs in the study come from an internet archive downloaded in 2007, containing over six thousand self-injury images (2011a; b; 2014a). ${ }^{6}$ In this article I will focus on photographs showing words cut into the skin [Figs. 1-4], a category that is included in approximately 15 percent of the images in the study. Apart from the words FAT and DIE, these photos are typical of the photographs in the study, which predominantly show a cut-up limb from a first-person viewpoint. The findings from the analyses will be compared to the statements of people who describe self-injuring experiences. These statements are taken from two sources: the results from a questionnaire about production and reception of self-injury photos carried out in 2008 (see Sternudd 2012) and selfbiographical accounts published in A Collection of Personal Stories (Wulff 2004; see also Sternudd 2014a, 16 for a presentation of this material).

The analysis is based on Kress and van Leeuwen's theory of multimodality (2001, 1-11), ${ }^{7}$ which is adapted to the material described in Fig. 5. The model is structured in the form of three statements. The first is words that are cut into the skin of a person; this is a multimodal statement in which verbal, nociceptive and visual modes are put into action. Mode is understood as the type of information that reaches the senses. The medium for distribution is text, nerves, wounds and blood, or scars, manifestations primarily perceived by the cutters themselves. The "actual material production of the semiotic artefact" (Kress and van Leeuwen 2001, 6 , my emphasis) is made through the use of the body and a sharp tool. Statement no. 1 uses material qualities; flesh and blood stress the importance and severity of the practice. The production is full of meaning; it signifies a serious business or a norm-breaking, deviant activity. Capital letters, common in internet practice, are read as talking loudly or screaming. As capital letters are probably easier to cut in than lower-case letters, intentional meaning should probably not be stressed

6 To secure anonymity, the name and address of the archive is not revealed.

7 Notably, Kress and van Leeuwen define articulation slightly differently from the definition used in this article. 
too much. The words were analysed using content analytic method (Bryman 2012, 288-309). Categories emanated partly from the data and partly from the theoretical framework (affect, feeling and emotion). The second statement is the words cut into the photographed skin; the modes are verbal and visual, the medium is text and image, and they are produced with the help of a camera. The photos are presumably taken with a digital camera, as suggested in Fig. 5, or are digitalized later. This makes it possible to reach the third statement, the photograph of words cut into the skin published on the internet. The modes and medium are the same as in the second statement, but here they are produced using a computer or other device that makes online publishing possible. A fourth category comes into play here: distribution. All aspects of the statements and the remediation of the statements are potential venues for production of meaning that can contribute to articulations of pain. In what follows, some aspects of this possible meaning production will be addressed. I use the expression possible meaning as it is important to note that the interpretation given here does not imply that all people who cut embrace the same view.

The disposition of the analysis follows the order presented in Fig. 5. The analysis of Statement 2 and Statement 3 draws to some extent on previous studies and, because of that, the analysis of Statement 1 becomes disproportionately large; however, this does not indicate that it is more important.

\section{Statement 1: Word Cut into Skin}

The archive contains 765 photos of words cut into the skin [Fig. 6]. ${ }^{8}$ A content analysis showed that the most common $(n=233,37 \%)$ were words associated with feelings, followed by words associated with emotions ( $\mathrm{n}=105,17 \%)$ and affects $(n=28,5 \%)$. Other categories were names, initials and subjects $(n=76$, $12 \%)$, statements addressed to somebody and words indicating activity $(\mathrm{n}=37$, $6 \%)$, leaving 69 words (11\%) uncategorized.

The most common feeling, indicated by the words, was disgust $(20 \%)$, presumably directed to the individual, stated through self-loathing words. FAT is the most frequent word in this category, often written on a thigh. This interpretation is made on the presumption that the word indicates the unwantedness of the

8 This figure represents approximately $15 \%$ of all photos in my study, which is a significantly higher prevalence than in Bandalli's (2011) and Seko's (2013) studies. Without further research on the matter, it is hard to say whether this is due to the fact that the material I studied was produced earlier than that used by Bandalli and Seko or whether the difference can be explained by variations in practices in different places on the internet (Flickr vs. a support and help forum). 
apprehended fatness. And in accordance with the views of Bordo (1997) and Nead $(1992,10)$, being fat is equated with lacking control in a hegemonic Western discourse. A fat body is a body that is out of control. Words such as UGLY, LOSER, WHORE and other words indicating sexual libidinousness were included in this category. The articulations of disgust fit into a discourse in which mental distress is associated with physical or social shortcomings. This relates to notions of social isolation that were reflected by words such as ALONE and LONELY, which were categorized as feelings of sadness $(\mathrm{n}=72,13 \%)$. Other feelings indicated by words were more outgoing, such as FUCK OFF and FTW, categorized as anger.

Words which appeared related to emotions were HATE $(11 \%)$ and LOVE $(8 \%)$. PAIN (5\%) was the only affect word mentioned. Other words with a high frequency were DIE and DEATH $(\sim 9 \%)$. When words appeared in sequence, the statement was often directed to someone, such as in KILL ME or I HATE U/ME. ${ }^{9}$

Presumably, the verbal mode produces additional meaning compared to the visual and occasionally nociceptive mode of the cut. Words "can tell more than slices alone," as a thirteen-year-old cutter states (Maigo 2006). In a sample of 44 statements, most of them from Wulff (2004), the cut in words was often just mentioned without any further explanation $(n=14)$. In other cases, the significance of the words was made clearer. The words were often used as descriptions, referring to feelings $(n=10)$ or how the person recognized themselves or was recognized by others $(n=8)$, or describing something wanted and/or feared $(n=1)$. In other cases, the words were related to something artistic or aesthetic $(n=3)$ or to memories $(\mathrm{n}=2)$, such as names or initials, for instance of boyfriends, or people who died $(n=2)$. In one case it was stated that the words were an apology, and in another it was said that the cutting had been done for other communicative reasons $(n=1)$. Some just stated that it felt good to cut in words $(n=2)$.

One example of the statements describes a friend's suicide. Heather wrote: "Then Grace died. [...] No one knew what did it. We all thought it was suicide, because she had attempted before. My life came crashing down. She was fifteen years old, her whole life was in front of her. I felt so guilty, like I should have called her more, written her, done something. I started by carving her name into my arm. Then other words. Guilty. Pain. Death. Nevermore." (Wulff 2004, 289.) The devastating moment is described as a crash; everything is turned upside down. The experience was first articulated in a word associated with a feeling

9 Compared to the results of Bandalli's study, my results showed that the appearance of words connected to self-loathing (similar to Bandalli's category "derogatory statements") was more frequent, as were words such as anger and hate. The large category in my study that includes names, initials and subjects is not found in Bandalli's study. 
and was materialized in the flesh in the word guilt. Then follows a series of words which form a narrative of sorrow.

Some of the words categorized as descriptive in this study are pejorative names which posit the person involved as an outcast and as being disgusting to others and therefore to themselves. Erikka wrote: "I would write things like "loser" or "hate me" or "worthless," because that's how I see myself. I mean, my own parents think that way, so why shouldn't I?” (Wulff 2004, 242.)

Through the deviant act, Erikka embraces the stigmatic signs of disgrace. The act can be seen as an attempt to take power over the naming by an articulatory act, produced with a sharp tool. Steffani describes in a similar way how she defines herself through the word SELF manifested in scars on sore skin: "I hurt myself on the outside to make the hurt on the inside stop. Maybe feeling sane, is what other people consider insane. Self, know who you really are ... and show it" (Steffani 2006).

In all of these examples, the words seem to be related to experiences of something painful: the death of a friend, parents who despise you and an inside which is hurting. The words which have been cut in are articulating the experience in a physical way and, to outsiders, possibly in a drastic way. The word "see" appears in two of the examples, which indicates that the visual mode is important. The frequent use of the words DEATH and DIE could also be an attempt to articulate the affect, the pain through moments that are often equivalent to something chaotic and speechless chaos (which follows when one passes away).

\section{Statement 2: Photograph of Word Cut into Skin}

The next type of statement is words cut into the skin remediated into a photograph, which allows for the possibility of producing new meanings. In the analysis, I rely on the above mentioned questionnaire. Even if answers did not explicitly mention photographs with words cut into skin, the result may provide guidance when it comes to the effect of photographic remediations of self-cutting.

The answers in the questionnaire revealed that people who have cut themselves can have a craving to re-experience the act. Interestingly, a number of informants stated that photos of their own or others' cuts could be a substitute for this feeling and thereby prohibit an actual performance of the act. One informant who had been cutting herself for a long time stated that a "feeling of being physically damaged" can be likeable and that "a permanent scar" can be something positive as it "will provide that feeling." If photographs can be a substitute for fresh 
wounds and visible scars, they become valuable proof: "they are an evidence that i [sic!] was in pain," as another informant stated. This and other statements articulate physical self-injuries as injuries that are easier to handle than mental injuries and that photographs can replace "real" scars (Sternudd 2012).

Due to their perceived indexical quality, photographs often produce effects of realness; this quality can be expanded to such extent that for some informants their own self-injury photographs would appear more real than the actual view of the wounds. The distancing effect of photography as a medium, distancing both the cut in time and from the skin, seems to make it possible to actually see the injury. One informant explained that she can "idealize" self-injury: "it appears as an 'abstract idea of the pain I deserve," - "viewing [photos of self-injury] makes [self-injury] more real” (Sternudd 2012, 431-432).

From these statements we can see that the transformation to a photo could convey and sometimes replace the cutting experience, and that it could also constitute a meaning of realness (even more so than the experience of when the cut was made). Some effects of the remediation are the possible extension of the act over time and the creation of a greater awareness of the act itself.

\section{Statement 3: Photographs of Word Cut into Skin on a Remote Screen}

Through the distribution of photographs on the internet, new meaning is produced. As Kress and van Leeuwen argue, distribution is not innocent; it not only distributes an identical sign but, on the contrary, the meaning of the mediated message is re-articulated $(2001,7)$. In this case, the capacity of the internet to link people together on a global scale is important for meaning-making. The internet has enabled otherwise marginalised people with deviant behaviour to find peers who share the same (or what is felt to be the same) experiences, interests, activities, etc. (Adler and Adler 2008). For this study, the self-injury communities which came into being in the wake of the social and cultural awareness of selfinjuring behaviour in the late 1990s and early 2000s were examined..$^{10}$ Until then, self-destructive behaviour was something you did, not an identity. An informant in the study of Adler and Adler explained that the community she was involved in helped her to "connect my identity to a self-abuser." Before that, she "didn't really think it was a problem, just a habit" $(2008,41)$.

In the self-injury communities and other places on the Internet which include user-generated material, photographs of self-injury can become part of a collective

10 For an overview of these communities see Adler and Adler 2011. 
articulation and thus a discursive tool for the production of and negotiations about the meaning of self-cutting. The huge numbers of self-injury photos published on internet provide an archive for validation and assessment for people who self-injure. For instance, they can be part of a valuation of self-injury identity; comparing your own wounds with others' could reveal whether you are a real self-injurer (that is to say, bad enough) or not. In these ways, self-injury photos have instrumental as well as identification values (Sternudd 2012).

As part of an internet community culture, self-injury photographs are often articulated in a discourse of confessions, which is an important feature of most self-help communities. These communities make it possible to show your wounds to others who have had a similar experience and still keep them hidden. A twentyone-year-old informant stated: "I wanted to show my secrets to someone, anyone, even though they didn't know me." The reason for this wish can be an act of solidarity: by publishing self-injury photos you return to others a gift you received from others. "I remember looking through pics there and felt as if I was not alone," said another informant. The loneliness that is referred to above, in the analysis of Statement 1, is alleviated through the interaction in the community. Self-injury photographs become a resource for identification. A person who cut herself formulated it like this: "I came across a picture that looked almost identical to my own cuts. And I realized, 'I am like that'” (Ariel on Psyke.org 2006).

This is an example of how photographs of self-injury are meaningful because they are understood as depictions of shared experiences of bodies hurt and in pain. In this way, someone who has cut herself and who looks at these photos can "imagine what exactly was going through that person's head when they caused the injury to themselves" (Sternudd 2012, 428). Publishing self-injury photos becomes something that community members do, but sometimes, in these communities, the deviant character of cutting vanishes.

Publishing and consuming self-injury photographs therefore becomes an articulatory practice which is associated with a certain self-injury identity. It is problematic for Bandalli that he cannot rule out the idea that cut-in words might have been done with the purpose of communicating with an internet forum, because in that case the words would not reflect the inner feelings of the one who cuts (Bandalli 2011, 127-128). With reference to Whitlock, Powers and Eckenrode (2006), this comes into conflict with the presupposed behaviour of a typical selfinjurer, which is keeping their activity a secret. In this way, both the community itself and the photographs of wounds, blood and words become part of a negotiation of self-injury and alternative discourses on mental pain. Even if concepts of inner, 
true and authentic feelings and an expressive model on self-injury do not apply on the communities, these internet places provide an opportunity to study alternative articulations of pain. When the articulatory practices of self-cutting contain words, this provides an opportunity to study how "proper" ways of framing pain are constructed and probably also regulate the way in which pain can be properly performed in the community in which the photos appear. To the question of whether self-injury photographs had influenced her, an informant in my study answered "yes, from photos I started writing words on myself."

Distribution through computer-accessible networks opens up opportunities for certain meaning-productions. The computer medium itself activates values of intimacy that contribute to making the internet a successful location for selfinjurers to establish their own places. This intimacy has to do with the users' closeness to the screen, according to Michele White (2006, 78), which differentiates the computer screen from mediums that distance the viewer (this is known as the male gaze). White's theory of intimacy is easy to apply to the photos of selfinjury. In relation to the most common type of self-injury photo, the spectator only has to look down at her own arm to see herself in the same way. The visual structure, combined with qualities of the medium itself, therefore cooperates to establish a discourse of a community of self-injurers - being together, not alone.

In this section, we have seen how the distribution of photographs of words cut into the skin to a remote screen on the internet makes the meaning of shared experiences and communal identification possible. The feeling of loneliness can be changed into the feeling of belonging.

\section{Conclusions}

In Statement 1, we saw how the words cut into the skin are used to understand the affect, the pain, by articulating them as a feeling. This is a process in which discourses articulate pain as feelings which are available in a hegemonic understanding of adolescence in distress: as self-loathing, self-blaming and selfpitying - the pain is articulated as individual shortcoming. We also saw how the meaning of cut-in words changed when they were photographed, and how their meaning was shifted towards the meanings of realness and indexical values that made the experience of cutting become extended over time. The meaning of the wounds and words changed again when photos of them were published on the internet, when they were being communicated in communities made up of peers, which extended the experience in space. Self-injury images became the property 
of a group which recognizes that its members share the same experience. The photos, as well as the experience, could in this context be valued as something desirable, a notion that challenges a hegemonic apprehension of self-injury.

So, the experience of cutting seems to be carried from Statement 1 to Statement 3 not as a mediation of this experience, but instead, as a remediation that influences articulations of feelings and emotion. The affect, the pain was transformed in my example, through the described stages, from articulations of individual, selforientated, negative emotions to collective expressions of solidarity, identity and intimacy. This transformation can be troubling to hegemonic order, as described at the end of the poem Nation by Vivica (2007):

"when we are everywhere from

broken down apartments

in the dark parts of Queens

to the big southern mansions

that are put upon hills in Georgia

pent up in our rooms

screaming \& jumping to our fucking self-loathing

rock'n roll that screams out suicide

we are the future

\& the future is going to be pretty fucked up."

\section{References}

Adler, Patricia A. and Peter Adler. 2008. The Cyber Worlds of Self-Injurers: Deviant Communities, Relationships, and Selves. Symbolic Interaction vol. 31 no. 1: 33-56.

Adler, Patricia A. and Peter Adler. 2011. The Tender Cut: Inside the Hidden World of Self-Injury. New York: New York University Press.

American Psychiatric Association. 2013. Diagnostic and Statistical Manual of Mental Disorders, Fifth Edition. Arlington, VA: American Psychiatric Association.

Baker, Thomas G. and Stephen P. Lewis. 2013. Responses to Online Photographs of Non-Suicidal Self-Injury: A Thematic Analysis. Archives of Suicide Research vol. 17 no. 3 (July): 223-235. doi:10.1080/13811118.2013.805642

Bandalli, Peter K. 2011. A Phenomenological Analysis of the Expressive and Communicative Functions of Deliberate Self-Harm. PhD Dissertation. University of Bath: Department of Psychology. 
Bolter, Jay David and Richard Grusin. 1996. Remediation. Configurations vol. 4 no. 3: 311-358.

Bordo, Susan. 1997. Reading the Slender Body. In Identity and Difference, ed. Kathryn Woodward, 167-181. London: Sage in association with the Open University.

Bryman, Alan. 2012. Social Research Methods. Oxford: Oxford University Press. Darche, Mary A. 1990. Psychological Factors Differentiating Self-Mutilating and Non-Self-Mutilating Adolescent Inpatient Females. Psychiatric Hospital no. 21: 31-35.

Lewis, Stephen P., Nancy L. Heath, Michael J. Sornberger and Alexis E. Arbuthnott. 2012. Helpful or Harmful? An Examination of Viewers' Responses to Nonsuicidal Self-Injury Videos on YouTube. Journal of Adolescent Health no. 51: 380-385.

Favazza, Armando R. 1996 [1987]. Bodies under Siege: Self-Mutilation and Body Modification in Culture and Psychiatry. Baltimore and London: The Johns Hopkins University Press.

Favazza, Armando R. and Karen Conterio. 1989. Female Habitual Self-Mutilators. Acta Psychiatrica Scandinavica no. 79: 283-289.

Kress, Gunther R. and Theo van Leeuwen. 2001. Multimodal Discourse: The Modes and Media of Contemporary Communication. London and New York: Bloomsbury Academics.

Laclau, Ernesto and Chantal Mouffe. 2001 [1985]. Hegemony and Socialist Strategy: Towards a Radical Democratic Politics. London and New York: Verso.

Maigo. 2006. Psyke.org - Maigo. http://psyke.org/pictures/m/maigo. Last accessed 03. 03. 2015.

Meeker, Mary. 2013. 2013 Internet Trends. Kleiner Perkins Caufield \& Byers. http://www.kpcb.com/insights/2013-internet-trends. Last accessed 03. 03. 2015.

Murray, Susan. 2008. Digital Images, Photo-Sharing, and Our Shifting Notions of Everyday Aesthetics. Journal of Visual Culture vol. 7 no. 2: 147-163.

Nead, Lynda. 1992. Female Nude. Art, Obscenity and Sexuality. London and New York: Routledge.

Öhman, Anneli Brännström, Maria Jönsson and Ingeborg Svensson. 2011. Inledning. In Att känna sig fram: Känslor i humanistisk genusforskning [Introduction. In To Feel One's Way: Feelings in Humanistic Gender Studies], eds. Anneli Brännström Öhman, Maria Jönsson and Ingeborg Svensson, 7-19. Umeå: Bokförlaget H:ström. 
Psyke.org. 2006. Picture Feedback. http://www.psyke.org/about/feedback/ pictures/. Last accessed 03. 03. 2015.

Seko, Yukari. 2013. Picturesque Wounds: A Multimodal Analysis of Self-Injury Photographs on Flickr. Forum Qualitative Sozialforschung vol. 14 no. 2 (May). http://www.qualitative-research.net/index.php/fqs/article/view/1935/3546. Last accessed 03. 03. 2015.

Shouse, Eric. 2005. Feeling, Emotion, Affect. M/C Journal vol. 8 no. 6 (December). http://journal.media-culture.org.au/0512/03-shouse.php. Last accessed 03. 03. 2015.

Steffani. 2006. Psyke.org - Steffani. http://www.psyke.org/pictures/s/steffani/. Last accessed 03. 03. 2015.

Sternudd, Hans T. 2010. The Discourse of Cutting: A Study of Visual Representations of Self-Injury on the Internet. In Making Sense of Pain: Critical and Interdisciplinary Perspectives, ed. Jane Fernandez, 237-248. Oxford, United Kingdom: Inter-Disciplinary Press.

Sternudd, Hans T. 2011a. Images of Pain: Self-Injurers' Reflections on Photos of Self-Injury. In Pain: Management, Expression, Interpretation, eds. Andrzej Dańczak and Nicola Lazenby, 237-248. Oxford, United Kingdom: InterDisciplinary Press 2011.

Sternudd, Hans T. 2011b. The Discourse of Cutting: Regaining Control and Meaning Making. In How Does It Feel?: Making Sense of Pain, eds. Hans T. Sternudd and Angela Tumini, 75-98. Oxford: Inter-Disciplinary Press.

Sternudd, Hans T. 2012. Photographs of Self-Injury: Production and Reception in a Group of Self-Injurers. Journal of Youth Studies vol. 15 no. 4: 421-436.

Sternudd, Hans T. 2014a. "I like to see blood": Visuality and Self-Cutting. Visual Studies vol. 29 no. 1: 14-29.

Sternudd, Hans T. 2014b. Modes of Pain: Reflections on the Self-Injury Experience. In Painful Conversations: Making Pain Sens(e)ible, ed. Hans T. Sternudd. 151-169. Oxford, United Kingdom: Inter-Disciplinary Press.

Sonesson, Göran. 1992. Bildbetydelser: Inledning till bildsemiotiken som vetenskap. [The Meanings of Images: Introduction to Semiotics of Images as Science], Lund: Studentlitteratur.

Tomkins, Silvan S. 1995. Exploring Affect: The Selected Writings of Silvan S. Tomkins. Cambridge: Cambridge University Press.

Vivica. 2007. Nation. Psyke.org, Poetry. http://www.psyke.org/poetry/v/vivica. Last accessed 03. 03. 2015. 
Walsh, Barent W. and Paul M. Rosen 1988. Self-Mutilation, Theory, Research and Treatment. New York and London: The Guilford Press.

White, Michele. 2006. The Body and the Screen: Theories of Internet Spectatorship. Cambridge, Massachusetts: MIT Press.

Whitlock, Janis L., Jane L. Powers and John Eckenrode. 2006. The Virtual Cutting Edge: The Internet and Adolescent Self-Injury. Developmental Psychology vol. 42 no. 3: 1-11.

Wulff, Morten ed. 2004. A Collection of Personal Stories. Greve: Psyke.org Press. http://www.psyke.org/download/personal. Last accessed 03. 03. 2015.

\section{List of Figures}

Figures 1-4. Words cut into the skin. (Printed with permission from the photographer @ 2012 Sternudd).
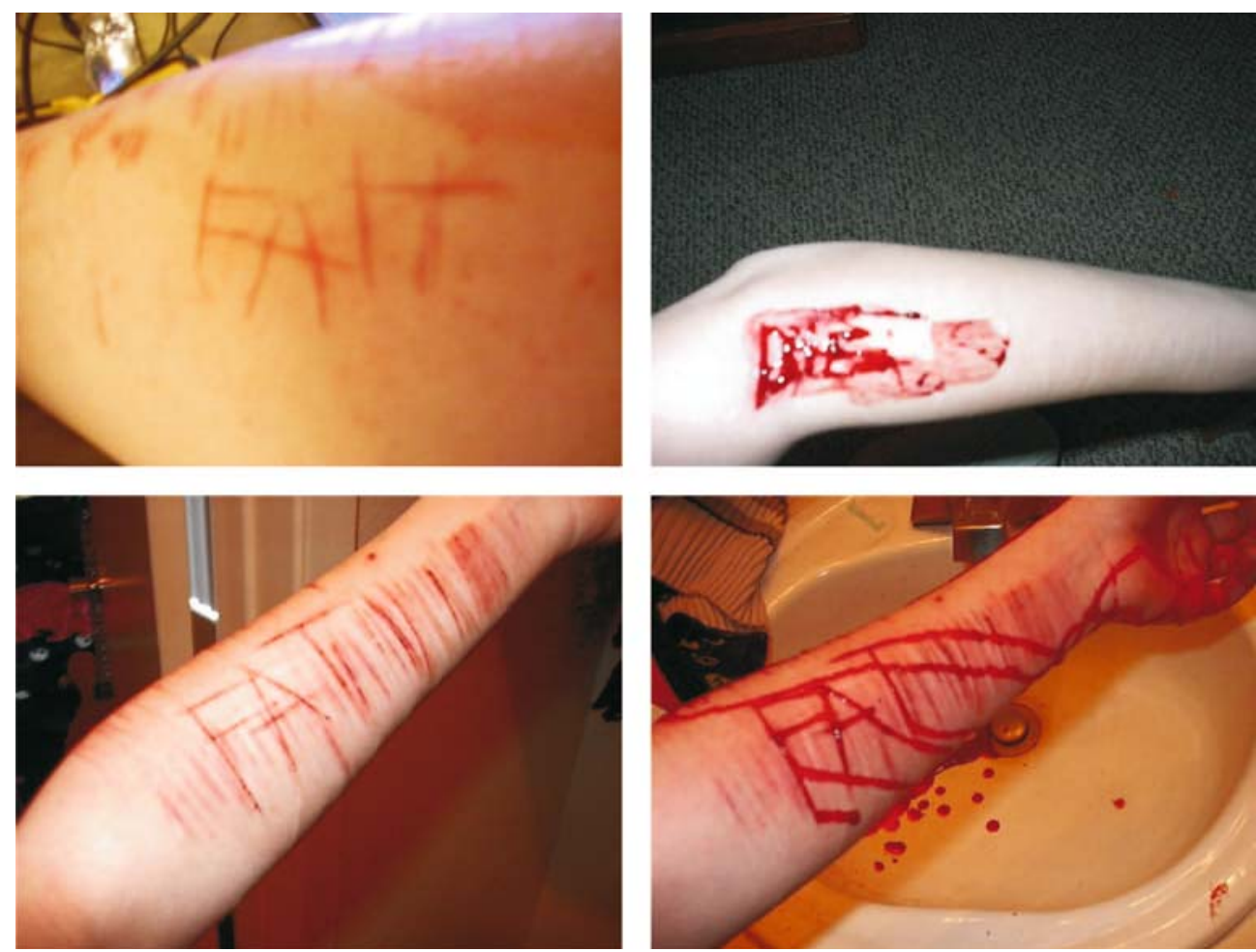
Figure 5. A model that shows the relation between the key concepts in the study.

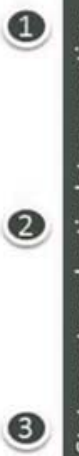

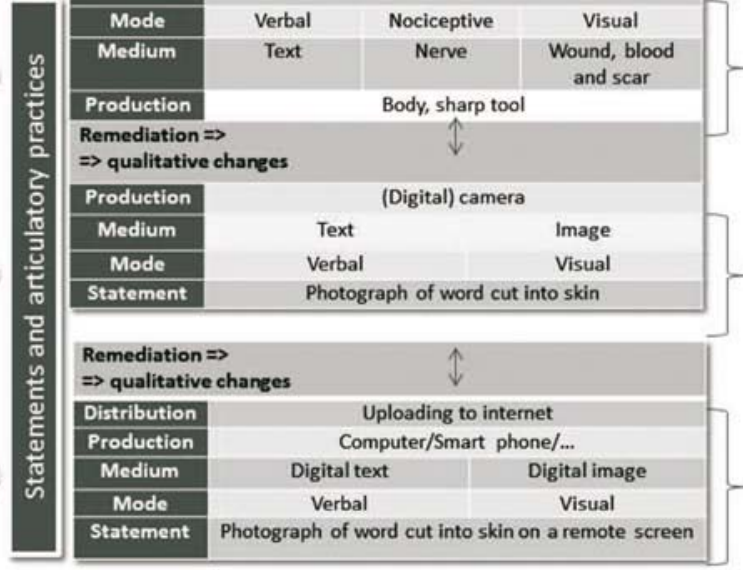

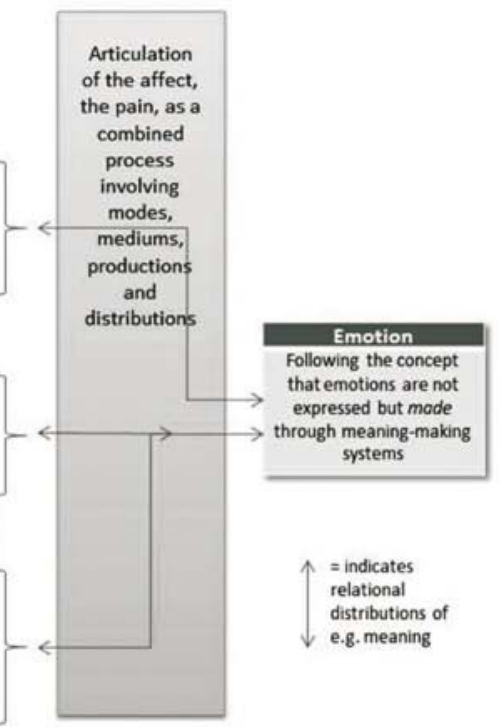

Figure 6. The words that were cut into the skin as a word cloud created using Wordle $^{\mathrm{TM}}$ (http://www.wordle.net).

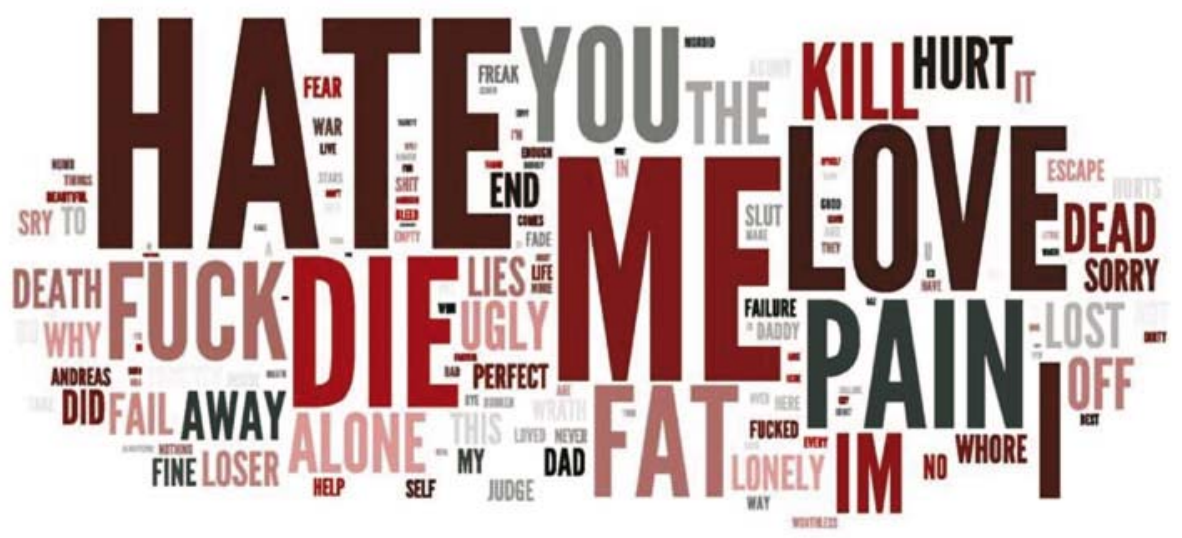

